\title{
Masters Athletes: No Evidence of Increased Incidence of Injury in Football Code Athletes
}

\author{
Joe Walsh ${ }^{1}$, Mike Climstein ${ }^{2}$, Ian T. Heazlewood ${ }^{3}$, Mark DeBeliso ${ }^{4}$, Jyrki Kettunen ${ }^{5}$, \\ Trish G. Sevene ${ }^{6}$, Kent J. Adams ${ }^{6}$ \\ ${ }^{1}$ Independent Researcher, Sydney, Australia \\ ${ }^{2}$ Faculty of Health Sciences \& Medicine, \\ Bond University Research Centre for Health, Exercise and Sports Science, Gold Coast, Australia \\ ${ }^{3}$ Faculty Education, Health and Science, School of Environmental and Life Sciences, Charles Darwin University, \\ Darwin, Australia \\ ${ }^{4}$ Department of Physical Education and Human Performance, Southern Utah University, Cedar City, USA \\ ${ }^{5}$ Arcada University of Applied Sciences, Helsinki, Finland \\ ${ }^{6}$ Kinesiology Department, California State University Monterey Bay, Seaside, USA \\ Email:mclimste@bond.edu.au
}

Received October $26^{\text {th }}, 2012$; revised November $30^{\text {th }}, 2012$; accepted December $10^{\text {th }}, 2012$

\begin{abstract}
The World Masters Games, held quadrennially, is the largest international sporting competition in terms of participant numbers. Yet this cohort remains proportionately under investigated. An online survey using an open-source specialized survey application software program was utilized to investigate the 2009 Sydney World Masters Games (SWMG) football code athletes (association football, touch football, rugby union). A total of 931 masters athletes $(28.2 \%$ response rate, aged $29-72$ yrs, mean $=47.6, \mathrm{SD} \pm 7.1$, $52.5 \%$ male) completed the survey, with touch football reporting the highest incidence of injury $(29.2 \%)$ followed by rugby $(27.0 \%)$ and soccer $(21.2 \%)$. Analyzing injury data (t-tests, chi square) identified patterns in injury location (legs $(11.2 \%, p<0.01)$ followed by knees, feet and ankles) and significant $(p<$ 0.01 ) classification patterns (muscle/tendon strain/tear $(13.0 \%, p<0.05)$, inflammation $(6.1 \%)$, joint pain $(6.0 \%)$ and ligament sprain/tear $(5.8 \%))$. There were also significant differences $(p<0.01)$ compared to general and elite sporting population data. For masters football athletes at the SWMG, the injury incidence during preparation for the tournament has similarities to, but is in fact significantly less than for these other sporting populations. Some gender and sport based differences in injury location and classification type were identified. There were also no significant age related changes in injury nature (classification type, location, incidence, time off work or training). Therefore these findings do not support the premise of masters football code athletes having a higher incidence of injury as compared to younger athletes.
\end{abstract}

Keywords: Sports; Exercise; Masters Athletes; Injury

\section{Introduction}

Masters athletes are those individuals systematically training for and competing in organized sporting events designed specifically for older adults (Raeburn \& Dascombe, 2008). Masters athletes have either pursued a physically active lifestyle for an extended period of time or have initiated exercise/sport in later life. Regardless of their motivation(s) for participation, this unique cohort of middle to older-aged adults remains proportionately under investigated with regard to the incidence of diverse chronic diseases and disorders as well as associated physiological measures of health.

There is growing evidence that regular exercise across the lifespan is beneficial for improved health and decreased incidence of various diseases and disorders (Liubicich, Magistro, Candela, Rabaglietti, \& Ciairano, 2012; Sawyer \& CastanedaSceppa, 2010; Williamson \& Pahor, 2010; Ryan, 2010). The genetic mechanisms that cause the aging process are uncertain (Kenyon, 2010) however its existence and the declines associated with aging are well established. Masters athletes may display an age related increase to the range of pathologies present in this population (e.g., heart disease) as well as physiological changes due to the aging process (e.g., sarcopenia) (Williamson \& Pahor, 2010; King \& Guralnik, 2010; Doherty, 2003). Due to these types of changes, it has been proposed that there is a predisposition to increased risk of injury associated with high level competitive sports performance, such as those required in football codes as well as other ball games (Kallinen \& Markku, 1995). Furthermore, an increased prevalence of injuries may be a factor contributing to reduced training intensity and volume, leading to reduced exercise performance in masters' endurance athletes (Tanaka \& Seals, 2008). Sports participation entails an increased risk of injury for elite, as well as recreational athletes (Bahr \& Krosshaug, 2005). Structural and functional changes may not only increase incidence of injury in older athletes, but also healing may be delayed in aged individuals (Kallinen \& Alén, 1994). Promisingly, no evidence of either achilles tendinopathy (Longo et al., 2009) or patella tendinopathy (Longo et al., 2011), being influenced by advancing age was found in masters track and field athletes. In contrast: "The adjusted risk for shoulder region (odds ratio 2.84, $p<0.03$ ) and Achilles tendon rupture $(14.87, p<0.01)$ after the age of 45 years was 
higher in the athletes than in the controls" (Kettunen, Kujala, Kaprio, \& Sarna, 2006). In the lay press, exercise at older ages is promoted as beneficial for an array of reasons, but in contrast it is often seen as deleterious to one's joints (Hunter \& Eckstein, 2009), with an associated supposed proneness to joint injuries (Marks, 2006). It has been stated that current management of knee pain in primary care tacitly confirms negative beliefs whilst also failing to promote the positive benefits of exercise (Hurley, Walsh, Bhavnani, Britten, \& Stevenson, 2010). This confusion as to the best approach to take can lead mature age individuals to avoid exercise (Hurley et al., 2010). There is no strong evidence indicating increased development of osteoarthritis in vigorous, low impact activities (Hunter and Eckstein, 2009). Physical activity plays an important role in the management and also pathogenesis of osteoarthritis, with the concomitant presence of joint injury increasing the risk of developing osteoarthritis in elite athletes (Hunter \& Eckstein, 2009).

Determining whether increased risk of acute or chronic injury legitimately exists and its magnitude is an important step in ascertaining the risk of participation in competitive exercise and thus may assist in developing a best practice model for optimizing health in the aging individual. One such best practice model (O'Shea, 2000) suggested that his proposed "all season, multi-activity cross-training prescription for the masters athlete" was a "passport to a healthy, active lifestyle."

The World Masters Games (WMG) is the largest international sporting competition in terms of participant numbers. In 2009, the Sydney World Masters Games (SWMG) attracted 28,676 competitors who represented 95 countries and competed in 28 sports (Sydney World Masters Games Organizing Committee, 2010). Previous research on the SWMG athletes has examined the health of North American competitors (Debeliso et al., 2011), as well as motivations for competition (Heazlewood et al., 2011; Adams et al., 2011) finding that socialising with other participants is a primary motivating factor. Provisional analysis of BMI of these athletes (Debeliso et al., 2012; Walsh et al., 2011a, 2011b) has shown promising trends.

\section{Aims of the Study}

There is concern that due to age-related changes, increased risk of injury will be associated with highly competitive sport for the aging athlete. The aim of this study was to provisionally investigate whether the frequency of injury in football code athletes was higher compared to previously reported data in the literature on either the general population, or amateur or elite sporting populations (Ekstrand, Hägglund, \& Waldén, 2011; King et al., 2010; Schneider, 2006). It was hypothesized that injury incidence rate per year would be less than professional sporting populations due to a presumption of lower playing and training hours compared to professional athletes. It was further hypothesized that injuries would be similar in location to a comparative (elite association football) population (Ekstrand et al., 2011).

\section{Methods}

\section{Nature of the Study and Settings}

This was a cross-sectional descriptive survey design. Three football codes from the SWMG were investigated: rugby union (rugby), association football (soccer) and touch football (touch).
The three sports investigated are all played internationally, however touch football has its greatest density of participants in Australasia, where it is a major amateur sport (Walsh, 2010). The survey was activated on the 15 October, 2009 and closed to participants on 26 February, 2010.

Ethics approval for the study was granted in accordance with the ethical standards of the Helsinki Declaration of 1975 (revised in 2008). The 2009 Sydney World Masters Games Organising Committee approved the project, stipulating the survey could only be provided in an online format. Accordingly, an online survey was created using Limesurvey ${ }^{\mathrm{TM}}$, an opensource, web based application. The online survey was utilized to investigate participants' demographics, medical health histories and injuries sustained in the preparation for the SWMG. Following pilot testing by investigators, electronic invitations were sent by the SWMG registration team to masters games athletes who provided a valid email address upon registration. The survey consisted of several sections related to the following areas: information for participants, a privacy statement, participant demographics, participant medical history (personal and family), past surgical procedures, prescribed medications, physiologic data, injuries sustained in the years of preparation for the tournament and psychological participation factors. Filters were used in the participant questionnaires to abbreviate response times. The 2009 SWMG survey process is illustrated in Figure 1.

\section{Data Analysis}

Statistical analysis was assisted with use of the software package SPSS (Ver. 18.0.0). Comparisons of classification count data was conducted using Pearson's chi square statistic. This was deemed appropriate and reliable due to the large sample sizes involved. Significant differences between groups were attained using an independent t-test or an appropriate non-parametric alternative, dependent on parameters for the application of a t-test not being met. Normality was assessed by investigating kurtosis, skewness, Q-Q plots, as well as the Kolmogorov-Smirnov test with the Lilliefors significance correction. Heteroscedasticity was assessed using Levene's test for the equality of variances.

\section{Results and Discussion}

A total of 931 SWMG athletes competing in football codes (which this paper is restricted to) completed the online survey. Of the respondents from this sub-sample, $702(75.4 \%)$ indicated they were registered for association football, 77 (8.3\%), rugby union and $155(16.6 \%)$ touch football. One of the 702 association football masters athletes also competed in rugby union, whilst two of the 702 association football athletes also competed in touch football. These participants were included in the analysis.

A total of $489(52.5 \%)$ of the participants were male, while $442(47.5 \%)$ were female. The age range of the participants was $29-72$ yrs $($ mean $=47.6, \mathrm{SD} \pm 7.1)$. A total of $67.2 \%$ of the football code athletes indicated they were representing Australia at the SWMG, whilst $32.8 \%$ indicated that they were representing other countries. Subjects whom did not include their age and gender were excluded from analysis. Athletes who reported suffering an injury are represented in Figure 2. A total 


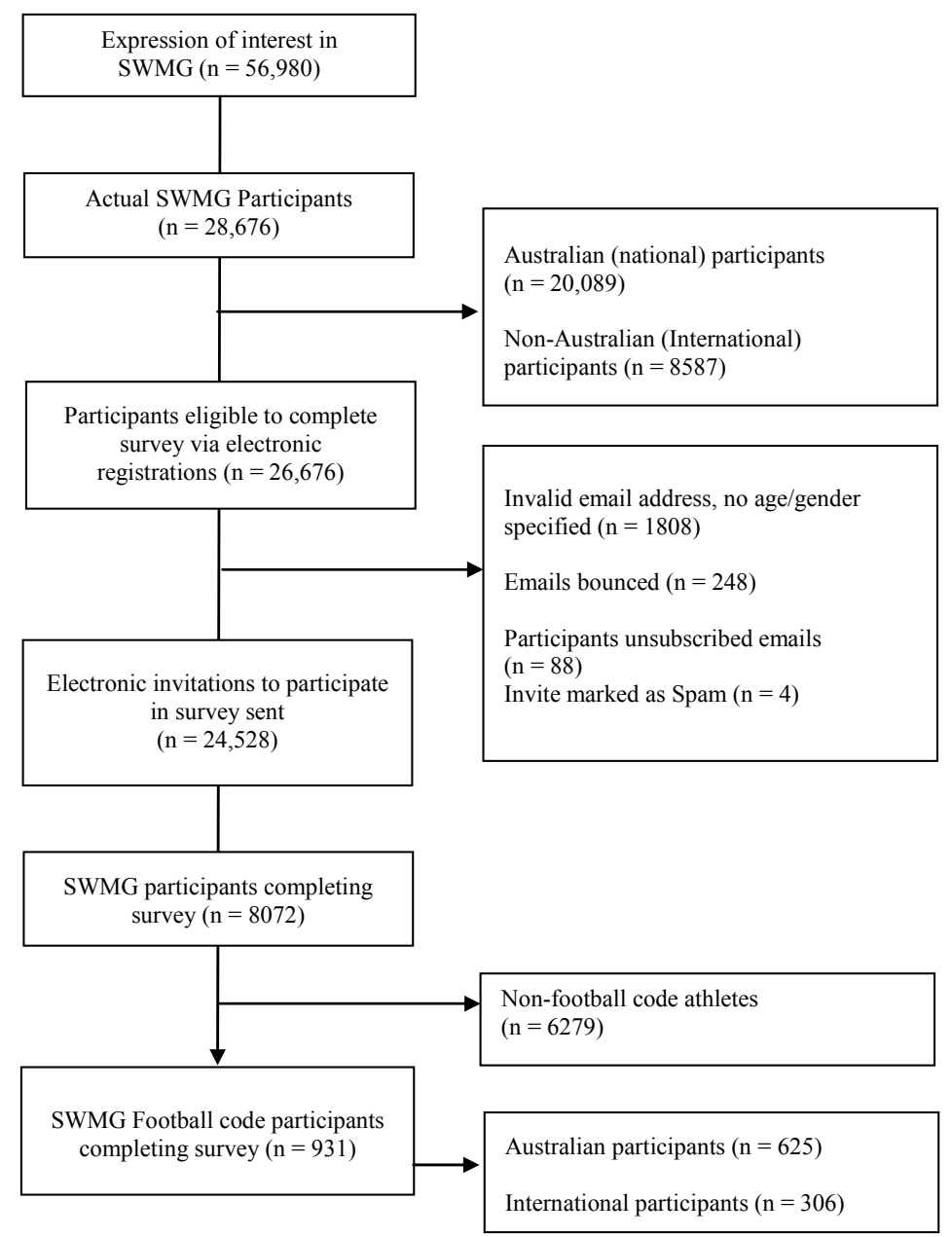

Figure 1.

Sydney world masters games survey overview.

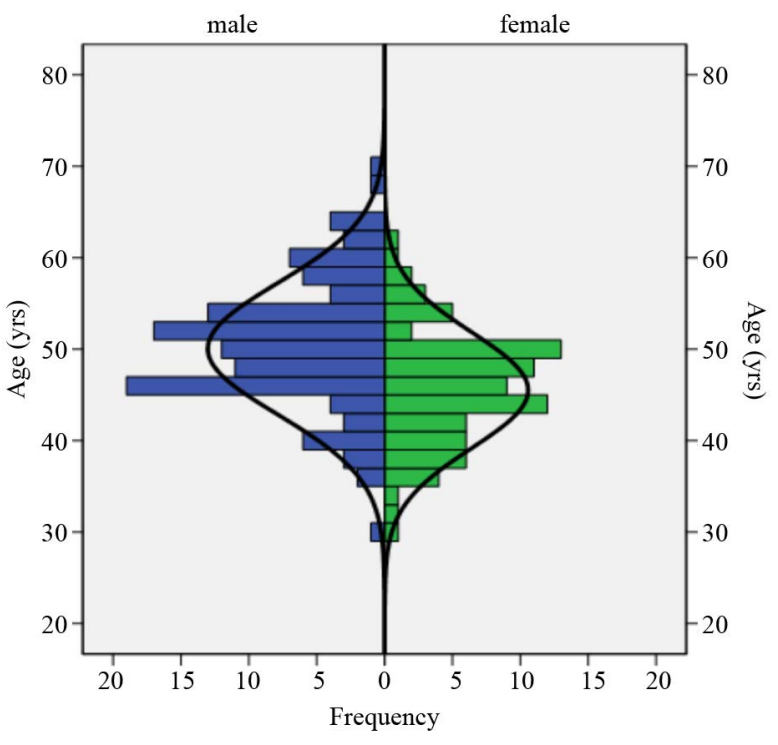

Figure 2.

Population pyramid displaying age and gender of athletes who have had an injury. Lines of normality illustrated. of $67.2 \%$ of the football code athletes indicated they were representing Australia at the SWMG, whilst 32.8\% indicated that they were representing other countries.

Analyzing injury demographics indicated that 215 football code athletes, namely $23.1 \%$ of respondents suffered at least one injury in the preparatory exercise training for SWMG. The highest percentage of injured players per sport was $29.2 \%$ in touch football, $27.0 \%$ in rugby and $21.2 \%$ in soccer. The elevated incidence of injury in touch football $\left(\chi^{2}=3.84\right)$ fell below the critical value for statistical significance of difference $\left(\chi^{2}=\right.$ 5.99), meaning this difference was not statistically significant. Touch players reporting an injury in preparation for the games were significantly older $(\mathrm{t}=2.43, p=0.016)$ than the rugby union and soccer players who reported injuries. Injury incidence might thus be proposed to be related to age, however although the 155 touch players were not significantly older (mean age of touch players 47.6 years, mean age of the other two football code athletes as a group 47.4 years, $\mathrm{t}=1.56, p=$ 0.120 ), the participants were not matched (age, gender) between the three sport groups, thus it would be inadvisable to draw any strong conclusions from this finding. Similarly, when examining the sub-sample in its entirety, injured males were significantly older than injured females (50.1 years vs. 45.5 years, $\mathrm{t}=4.631, p<0.001)$, however this may have been re- 
lated to the age of males in the football code sample being significantly higher than for females (49.7 years vs. 45.2 years, $\mathrm{t}=$ $10.18, p<0.001)$. There was no statistical difference in injuries sustained by age, for the football codes sub-sample as a whole or for either gender analyzed in isolation.

Of the thirteen classifications of injuries reported, the most common type of injury was muscle/tendon strain $\left(13.0 \%, \chi^{2}=\right.$ $232.8, p<0.0001)$, followed by inflammation $\left(6.1 \%, \chi^{2}=17.2\right.$, $p>0.05)$, joint pain $\left(6.0 \%, \chi^{2}=15.7, p>0.05\right)$ and ligament sprain/tear $\left(5.8 \%, \chi^{2}=13.1, p>0.05\right)$. Analysis also indicated a muscle/tendon sprain was significantly the most common injury $(p<0.05)$, while comparatively punctures $\left(0.1 \%, \chi^{2}=31.2\right)$, dehydration $\left(0.1 \%, \chi^{2}=31.2\right)$, lacerations $\left(0.3 \%, \chi^{2}=27.4\right)$ (all $p<0.01)$ and dislocation $\left(0.6 \%, \chi^{2}=22.2, p<0.05\right)$ were significantly less common.

In total, across all three football codes, 346 of the injuries were also designated by the survey participants according to specific body locations. Analysis indicated the most common site of injury were the legs $\left(11.2 \%, \chi^{2}=37.2, p<0.01\right)$, this figure excluded injuries to knees, feet and ankles, which were not significantly different to expected values (using a Pearson Chi Square statistic). From a perspective of comparing the 13 injury locations (face, head (other), chest, eye, abdomen/pelvis, hand, spine/back, hip and shoulder) were all proportionately under represented $(p<0.01)$ below the Pearson Chi Square expected value given by even distribution of injuries across location categories. Distribution of injuries sustained via classification of injury location on the body is illustrated in Figure 3.

Females reported a lower incidence of injuries than males $\left(20.1 \%\right.$ vs. $\left.25 \%, \chi^{2}=16.21, p<0.001\right)$. It should be noted however that males in the football code sub-sample were older and the 77 rugby players were all male. One might assume that these may have been confounding factors and influenced this gender difference in injury incidence, with a higher proportion of males involved in this collision sport and the greater mean

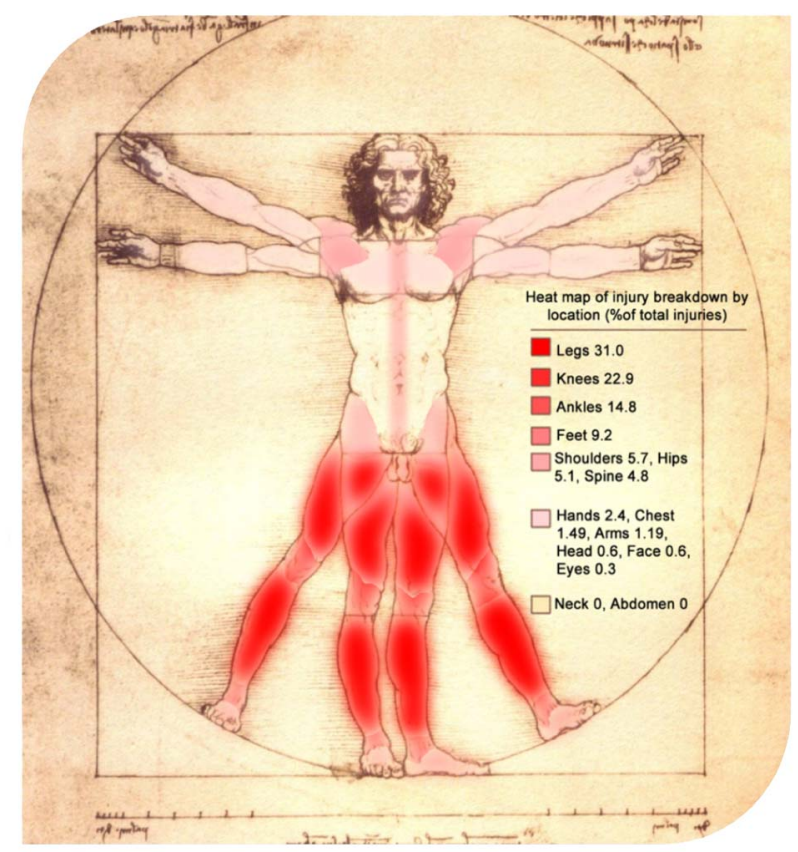

Figure 3.

Heat map of injury location including percentages of total injuries. age of males in the sample. This was unlikely though as there were no statistical increases in reported injuries amongst the rugby competitors. Analysis also indicated no significant difference in age between those athletes indicating they either did or did not suffer from an injury.

Analyzing differences in injury type and location revealed some additional gender differences. Males were more likely to suffer a muscle/tendon strain than females $\left(16.4 \%\right.$ vs. $9.3 \%, \chi^{2}$ $=8.96, p<0.01)$ and also more likely to sustain a leg $(15.3 \%$ vs. $\left.6.6 \%, \chi^{2}=16.01, p<0.001\right)$ chest $\left(1.0 \%\right.$ vs. $0 \%, \chi^{2}=4.52, p<$ $0.05)$ or hand $\left(1.4 \%\right.$ vs. $\left.0.2 \%, \chi^{2}=3.92, p<0.05\right)$ injury. However, males were less likely to sustain an injury to the foot/feet $\left(1.8 \%\right.$ vs. $\left.5.0 \%, \chi^{2}=6.86, p<0.01\right)$. Whilst there were clearly some gender based trends in injury type and location, due to the low cell counts in the Pearson Chi Square contingency table and the necessary adjustments by the number of comparisons made (thirteen classifications each of injury/injury locations by two genders), it would be advised to focus on gender differences in scores for muscle/tendon strain for type of injury and legs and foot/feet for location as more reliable patterns.

Tables 1-4 list the injury locations and classification types by sport and gender. Due to overlap between different age groups, genders and sports caution was taken not to draw conclusions from any apparent patterns, due to multiple variables affecting these trends (for example rugby athletes were exclusively male in this sample and males were predominantly older, influencing results by sport, gender and age).

\section{Table 1.}

Injury type classification by sports. Significant differences between codes of football were present, percentage and Pearson chi square values are highlighted in italics.

\begin{tabular}{|c|c|c|c|c|}
\hline $\begin{array}{c}\text { Injury } \\
\text { classification }\end{array}$ & $\begin{array}{c}\text { Soccer } \\
(\mathbf{n}=702) \\
(\%)\end{array}$ & $\begin{array}{c}\text { Touch } \\
(\mathrm{n}=155) \\
(\%)\end{array}$ & $\begin{array}{c}\text { Rugby } \\
(\mathrm{n}=77) \\
(\%)\end{array}$ & $\Sigma \chi^{2}$ \\
\hline $\begin{array}{l}\text { Abrasion/ } \\
\text { cuts }\end{array}$ & 2.1 & 1.8 & 2.3 & $24.5^{* * *}$ \\
\hline Concussion & 0.0 & 0.0 & 0.0 & 0.0 \\
\hline $\begin{array}{c}\text { Contusion/ } \\
\text { bruising }\end{array}$ & 4.9 & 0.7 & 1.4 & 5.1 \\
\hline Dehydration & 0.0 & 0.2 & 0.0 & 5.0 \\
\hline Dental injury & 0.0 & 0.0 & 0.0 & 0.0 \\
\hline Dislocation & 0.6 & 0.5 & 0.2 & 2.0 \\
\hline Fracture & 0.6 & 0.7 & 0.2 & 4.2 \\
\hline Inflammation & 7.6 & 2.5 & 2.0 & 5.0 \\
\hline Joint pain & 6.5 & 3.6 & 1.8 & $9.7^{* *}$ \\
\hline Laceration & 0.0 & 0.0 & 0.7 & $33.4^{* * *}$ \\
\hline $\begin{array}{c}\text { Ligament } \\
\text { sprain/tear }\end{array}$ & 8.6 & 1.4 & 1.4 & 1.6 \\
\hline $\begin{array}{c}\text { Muscle/tendon } \\
\text { strain }\end{array}$ & 17.0 & 5.9 & 2.7 & 2.9 \\
\hline Muscle pain & 5.5 & 2.9 & 0.7 & 5.8 \\
\hline Puncture & 0.0 & 0.0 & 0.2 & $11.1^{* * *}$ \\
\hline Sprain & 2.5 & 0.9 & 0.0 & 2.0 \\
\hline
\end{tabular}

${ }^{* *}$ indicates significance at the 0.01 level, ${ }^{* * *}$ indicates significance at the 0.001 level. 
Table 2.

Injury location by sports. Where significant differences between codes of football were present, percentage and Pearson chi square values are highlighted in italics.

\begin{tabular}{|c|c|c|c|c|}
\hline Injury location & $\begin{array}{c}\text { Soccer } \\
(\mathrm{n}=702) \\
(\%)\end{array}$ & $\begin{array}{c}\text { Touch } \\
(\mathrm{n}=155) \\
(\%)\end{array}$ & $\begin{array}{c}\text { Rugby } \\
(\mathrm{n}=77) \\
(\%)\end{array}$ & $\Sigma \chi^{2}$ \\
\hline Abdomen/pelvis & 0.1 & 0.7 & 0.5 & $11.3^{* *}$ \\
\hline Ankle & 7.8 & 2.0 & 0.7 & 0.4 \\
\hline Arm & 0.2 & 0.7 & 0.0 & $9.9^{* * *}$ \\
\hline Chest & 0.2 & 0.7 & 0.2 & $8.5^{*}$ \\
\hline Eye & 0.0 & 0.0 & 0.2 & $11.1^{* *}$ \\
\hline Face & 0.2 & 0.0 & 0.2 & 4.7 \\
\hline Foot/feet & 4.9 & 1.1 & 0.5 & 0.1 \\
\hline Hand(s) & 0.4 & 0.9 & 0.5 & $10.8^{* *}$ \\
\hline Head & 0.0 & 0.0 & 0.5 & $22.3^{* * * *}$ \\
\hline Hip & 2.7 & 0.7 & 0.2 & 0.1 \\
\hline Knees & 10.4 & 3.8 & 2.0 & 3.3 \\
\hline $\operatorname{Leg}(s)$ & 14.5 & 4.8 & 2.7 & 2.8 \\
\hline Neck & 0.0 & 0.0 & 0.0 & 0.0 \\
\hline Shoulder & 1.6 & 0.9 & 1.6 & $21.8^{* * * *}$ \\
\hline Spine/back & 1.4 & 1.6 & 0.5 & $9.6^{* *}$ \\
\hline
\end{tabular}

${ }^{*}$ indicates significance at the 0.05 level, ${ }^{* *}$ indicates significance at the 0.01 level, ${ }^{* * *}$ indicates significance at the 0.001 level.

Table 3.

Injury classification by gender. Where significant differences between genders were present, percentage and Pearson Chi Square values are highlighted in italics.

\begin{tabular}{cccc}
\hline Injury classification & $\begin{array}{c}\text { Male } \\
(\mathbf{n}=\mathbf{4 8 9}) \\
\mathbf{( \% )}\end{array}$ & $\begin{array}{c}\text { Female } \\
(\mathbf{n}=\mathbf{4 4 2}) \\
\mathbf{( \% )}\end{array}$ & $\mathbf{\Sigma} \chi^{2}$ \\
\hline Abrasion/cuts & 4.1 & 2.9 & 0.9 \\
Concussion & 0.0 & 0.0 & 0.0 \\
Contusion/bruising & 3.1 & 4.1 & 0.7 \\
Dehydration & 0.2 & 0.0 & 0.9 \\
Dental injury & 0.0 & 0.0 & 0.0 \\
Dislocation & 1.0 & 0.2 & 2.3 \\
Fracture & 0.8 & 0.7 & 0.1 \\
Inflammation & 5.9 & 6.3 & 0.1 \\
Joint pain & 6.1 & 5.9 & 0.0 \\
Laceration & 0.6 & 0.0 & 2.7 \\
Ligament sprain/tear & 5.3 & 6.3 & 0.4 \\
Muscle/tendon strain & $\mathbf{1 6 . 4}$ & $\mathbf{9 . 3}$ & $\mathbf{9 . 0}$ \\
Muscle pain & 4.9 & 4.3 & 0.2 \\
Puncture & 0.2 & 0.0 & 0.9 \\
Sprain & 1.0 & 2.5 & 2.9 \\
\hline
\end{tabular}

\footnotetext{
${ }^{* * *}$ indicates significance at the 0.001 level.
}

Table 4.

Injury type location by gender. Where significant differences between genders were present, percentage and Pearson chi square values are highlighted in italics.

\begin{tabular}{|c|c|c|c|}
\hline Injury location & $\begin{array}{c}\text { Male } \\
(n=489) \\
(\%)\end{array}$ & $\begin{array}{c}\text { Female } \\
(\mathrm{n}=442) \\
(\%)\end{array}$ & $\Sigma \chi^{2}$ \\
\hline Abdomen/pelvis & 1.0 & 0.2 & 2.3 \\
\hline Ankle & 4.3 & 6.6 & 2.2 \\
\hline Arm & 0.6 & 0.2 & 0.8 \\
\hline Chest & 1.0 & 0.0 & $4.5^{*}$ \\
\hline Eye & 0.2 & 0.0 & 0.9 \\
\hline Face & 0.4 & 0.0 & 1.8 \\
\hline Foot/feet & 1.8 & 5.0 & $6.9^{* *}$ \\
\hline Hand(s) & 1.4 & 0.2 & $3.9^{*}$ \\
\hline Head & 0.4 & 0.0 & 1.8 \\
\hline Hip & 1.4 & 2.3 & 0.9 \\
\hline Knees & 7.0 & 9.7 & 2.2 \\
\hline $\operatorname{Leg}(s)$ & 15.3 & 6.6 & $16.0^{* * *}$ \\
\hline Neck & 0.0 & 0.0 & 0.0 \\
\hline Shoulder & 2.9 & 1.1 & 3.4 \\
\hline Spine/back & 2.0 & 1.4 & 0.6 \\
\hline
\end{tabular}

*indicates significance at the 0.05 level, ${ }^{* *}$ indicates significance at the 0.01 level, ${ }^{* * *}$ indicates significance at the 0.001 level.

In an attempt to investigate whether injury classification and location were dependent upon age, the database was split into those under 50 years old $(<50$ yrs, $\mathrm{n}=578)$ and those 50 years of age and older $(\geq 50$ yrs, $n=353)$. Using Pearson Chi Square tests surprisingly there was no difference in the incidence of injury between those $<50$ or $\geq 50$. There were also no differences in the 13 locations or 13 classification types for the injuries sustained based upon age categories. Collectively, these results suggest that injury patterns between football code athletes $<50$ yrs and $\geq 50$ yrs, were not significantly different in incidence rate, location or classification, which is a promising finding. Further investigation was performed, analyzing trends in total injuries per decade. No statistical differences in the distribution over each decade were observed when compared to the Pearson Chi Square expected values. An independent t-test also indicated no significant difference in age between those athletes who were or were not injured. Therefore there was no significantly increased risk of injury for older masters athletes from preparation for the world masters games.

These findings are in agreement with previous research conducted by Ekstrand et al., 2011, who investigated high level open age sport. Ekstrand and colleagues' study was conducted on 23 teams selected by the Union of European Football Associations as being in the top 50 European association football clubs, finding that between 2001 and 2008 a thigh strain was the most common injury ( $17 \%$ of all injuries). This injury location (specifically legs, excluding knees, feet and ankles) and type (classification as muscle/tendon strain) is therefore consistently the highest occurring in both SWMG athletes prior to the games and open age professional athletes.

A total of 172 participants (18.5\%) indicated that they had 
been unable to complete exercise training on a number of days (range $1-365$, mean $=53.8, \mathrm{SD} \pm 79.2$ ) due to injury in preparation for the SWMG. The statistical range of the impact of these injuries was thus quite large. A total of 41 (4.4\%) participants had been unable to attend work over the same period due to sporting injuries (range $1-90$, mean $=11.9, \mathrm{SD} \pm 18.3$ ). This equates to the sample population on average missing an average of 2.5 training days and 0.1 work days per athlete per year. Comparatively, in 2010 the average Australian worker had an average absence rate of 9.9 days (at an average employer cost of $\$ 385 / \mathrm{d})$. Therefore, preparation for the SWMG did not significantly $(p<0.001)$ negatively impact employment absenteeism in context of total absences for all other reasons (Direct Health Solutions, 2011).

There were no statistical differences in the amount of days off work or off training between the injured athletes across the three codes. As expected there was a correlation between days lost training and days of lost work within the sample $(\rho=0.31$, $p<0.01)$. There were also no significant differences in the numbers of days of lost work or training between genders. There were also no correlations between days off work or training and age.

When compared to other studies, these findings indicate injuries are significantly lower in incidence than those for both professional athletes in professional football codes (Ekstrand et al., 2011; King et al., 2010) as well as amateur athletes in football codes (King et al., 2010) $(p<0.01)$. Our findings also compare favorably with data from national populations in terms of the reported incidence of total injuries sustained (Schneider, 2006).

Causation was also considered, namely it was possible that some masters athletes did not register to compete in the Sydney WMG due to injuries sustained in preparation for the tournament. This would have affected these results, in effect removing an undetermined number of injured athletes from the survey. Any causation of this nature however, was assumed to be slight, with such a large sample number. This was logical because of several factors. The sample number was large (namely with 346 injuries in 215 athletes from 931 football code athletes) which minimized the likelihood of effects purely due to random sampling. The nature of the most common injuries were found to be of a non-serious nature (strains, inflammation, sprains, muscles and tendons of the leg) and the incidence of injuries was recorded relatively long period meaning that with reasonable distribution only a small fraction of the minor injuries suffered would be close to the tournament, the majority happening with sufficient time to recover for the Sydney WMG. This was re-iterated by the mean number of days missed due to injury (53.8 days) and its dispersion ( $\mathrm{SD} \pm 7.92)$. These values indicated it was likely some athletes failed to compete due to injury, but that proportionally, in context of the total number of injuries sustained, this would not have been sufficient in magnitude to reverse the trend. That is the trend of favorable injury rates in the football codes sub-sample.

There was also the possibility that athletes with some inherent ability to resist injury were able to continue physical activity across the lifespan and were therefore more likely to be involved in masters sport. While many athletes did suffer injuries, it was previously confirmed that this was not a sole motivator for being involved in masters football (Heazlewood et al., 2011).

In addition, it should be noted that care should be taken to not read too much into gender based trends or sport based trends because of exclusively male participation in rugby union in addition to non-significant differences in age between sports and also significant differences between genders. There is still some uncertainty as to whether type of injury might be due to gender or sports classification. For this reason sport based trends should be considered in the context of a small sample (215 athletes, of different ages, by two genders and three sports). The purpose of this manuscript was primarily to evaluate injury risks in context of reported data on comparative populations, in order to assess the viability of the view that there would be increased injury risk amongst competitive masters athletes. This risk was not supported by this research and in fact reduced injury risks were apparent.

\section{Conclusion}

It is a commonly held conception that adherence to exercise reduces the incidence of chronic disorders as well as improving indices of general health. There was concern that due to age related changes, increased risk of injury will be associated with highly competitive sport for the aging athlete. For masters football athletes at the SWMG, it was shown that injury during the preparation for the tournament had similarities, but was in fact significantly less in incidence than for many other competing football populations as well as open age general sporting populations. There was also no increase in injury incidence, days of training missed due to injury or days of work missed due to injury as age was increased across the sub-sample from the SWMG. Nor were there any changes in injury location or classification type with advancing age. Therefore evidence indicated that these concerns are unfounded for athletes competing in soccer, rugby union and touch football.

\section{Acknowledgements}

The authors would like to thank those masters athletes who donated their time to complete the survey. We would also like to acknowledge the support provided by the Sydney World Masters Games Organizing Committee and the information technology assistance provided by Evan Wills which was instrumental in the successful completion of this project. The authors would also like to thank Paul Dundon of Direct Health Solutions for providing the comparative data on workplace absenteeism in Australia.

\section{REFERENCES}

Adams, K., Debeliso, M., Walsh, J., Burke, S., Heazlewood, I. T., Kettunen, J., \& Climstein, M. (2011). Motivations to participate in sport at the Sydney 2009 World Masters Games. Medical Science in Sports \& Exercise, 43, S655. doi:10.1249/01.MSS.0000402628.93915.fc

Bahr, R., \& Krosshaug, T. (2005). Understanding injury mechanisms: A key component of preventing injuries in sport. British Journal of Sports Medicine, 39, 324-329. doi:10.1136/bjsm.2005.018341

DeBeliso, M., Adams, K. J., Climstein, M., Walsh, J., Burke, S., Heazlewood, I. T., \& Kettunen, J. (2011). World masters games: North American participant medical and health history survey. Medical Science in Sports \& Exercise, 43, S374. doi:10.1249/01.MSS.0000401503.38438.d8

DeBeliso, M., Walsh, J., Adams, K. J., Climstein, M., Heazlewood, I. T., Burke, S., \& Kettunen, J. (2012). Body mass index of North American participants at the world masters games. American College of Sport Medicine 59th Annual Meeting and 3rd World Congress on 
Exercise Is Medicine. San Francisco, CA.

Direct Health Solutions (2011). 2011 Absence management survey. Sydney: Direct Health Solutions.

Doherty, T. (2003). Invited review: Aging and sarcopenia. Journal of Applied Physiology, 95, 1717-1727.

Ekstrand, J., Hägglund, M., \& Waldén, M. (2011). Injury incidence and injury patterns in professional football-The UEFA injury study. British Journal of Sports Medicine, 45, 553-558. doi:10.1136/bjsm.2009.060582

Heazlewood, I. T., Walsh, J., Climstein, M., Burke, S., Kettunen, J., Adams, K. J., \& DeBeliso, M. (2011). Sport psychological constructs related to participation in the 2009 world masters games. Proceedings of the 7th International Conference on Sport Medicine and Sport Science.

Hunter, D., \& Eckstein, F. (2009). Exercise and osteoarthritis. Journal of Anatomy, 214, 197-207. doi:10.1111/j.1469-7580.2008.01013.x

Hurley, M., Walsh, N., Bhavnani, V., Britten, N., \& Stevenson, F. (2010). Health beliefs before and after participation on an exercised-based rehabilitation programme for chronic knee pain: Doing is believing. BioMed Central Musculoskeletal Disorders, 11, 31. doi:10.1186/1471-2474-11-31

Kallinen, M., \& Marku, A. (1994). Sports-related injuries in elderly men still active in sports. British Journal of Sports Medicine, 28, 5255. doi:10.1136/bjsm.28.1.52

Kallinen, M., \& Marku, A. (1995). Aging, physical activity and sports injuries: An overview of common sports injuries in the elderly. Sports Medicine, 20, 41-52.

doi:10.2165/00007256-199520010-00004

Kenyon, C. (2010). The genetics of aging. Nature, 464, 504-512. doi: $10.1038 /$ nature 08980

Kettunen, J. A., Kujala, U. M., Kaprio, J., \& Sarna, S. (2006). Health of master track and field athletes. A 16-year follow-up study. Clinical Journal of Sport Medicine, 16, 142-148. doi:10.1097/00042752-200603000-00010

King, A., \& Guralnik, J. (2010). Maximizing the potential of an aging population. Journal of the American Medical Association, 304, 19541955. doi:10.1001/jama.2010.1577

King, D., Hume, P., Gianotti, S., \& Clark, T. (2010). A retrospective review over 1999 to 2007 of head, shoulder and knee soft tissue and fracture-dislocation injuries and associated costs for rugby league in New Zealand. Sports Medicine, 40, 163-178. doi:10.2165/11319740-000000000-00000

Liubicich, M., Magistro, D., Candela, F., Rabaglietti, E., \& Ciairano, S. (2012). Physical activity and mobility function in elderly people living in residential care facilities. "Act on aging": A pilot study. Advances in Physical Education, 2, 54-60. doi:10.4236/ape.2012.22010

Longo, U., Rittweger, J., Garau, G., Radonic, B., Gutwasser, C., Gilliver, S., Kusy, K., Zieliński, J., Felsenberg, D., \& Maffulli, N. (2009). No influence of age, gender, weight, height and impact pro- file in achilles tendinopathy in masters track and field athletes. The American Journal of Sports Medicine, 37, 1400-1405. doi: $10.1177 / 0363546509332250$

Longo, U., Rittweger, J., Garau, G., Radonic, B., Gutwasser, C., Gilliver, S., Kusy, K., Zieliński, J., Felsenberg, D., \& Maffulli, N. (2011). Patella tendinopathy in masters track and field athletes: Influence of impact profile, weight, height, age and gender. Knee Surgery, Sports Traumatology, Arthroscopy, 19, 508-512. doi:10.1007/s00167-010-1314-y

Marks, B. (2006). Health benefits for veteran (senior) tennis players. British Journal of Sports Medicine, 40, 469-476. doi:10.1136/bjsm.2005.024877

O'Shea, J. P. (2000). Quantum strength and fitness. Corvallis, OR: Patrick's Books.

Reaburn, P., \& Dascombe, B. (2008). Endurance performance in masters athletes. European Review of Aging and Physical Activity, 5, 3142. doi:10.1007/s11556-008-0029-2

Ryan, A. (2010). Exercise in aging: Its important role in mortality, obesity and insulin resistance. Aging Health, 6, 551-563. doi: $10.2217 /$ ahe. 10.46

Sawyer, K., \& Castaneda-Sceppa, C. (2010). Impact of aerobic physical activity on cardiovascular and noncardiovascular outcomes: Is anyone too old to exercise. Aging Health, 6, 251-260. doi:10.2217/ahe 10.10

Schneider, S. (2006). Sports injuries: Population based representative data on incidence, diagnosis, sequelae, and high risk groups. British Journal of Sports Medicine, 40, 334-339. doi:10.1136/bjsm.2005.02288

Sydney World Masters Games Organizing Committee (2010). Sydney 2009 World Masters Games Final Report. Sydney: Sydney 2009 World Masters Games.

Tanaka, H., \& Seals, D. (2008). Endurance exercise performance in masters athletes: Age-associated changes and underlying physiological mechanisms. The Journal of Physiology, 586, 53-63.

Walsh, J. (2010). A Markov States model for touch football. Proceedings of the 10th Australasian Conference on Mathematics and Computers in Sport. Darwin: Mathsport, 259-267.

Walsh, J., Climstein, M., Heazlewood, I. T., Burke, S., Kettunen, J., Adams, K. J., \& DeBeliso, M. (2011a). Variations in body mass index with age in masters athletes (world masters games). Journal of the World Academy of Science, Engineering and Technology, 7, 1115-1119.

Walsh, J., Heazlewood, I. T., Climstein, M., Burke, S., Adams, K. J., DeBeliso, M., \& Kettunen, J. (2011b). Body mass index for Australian athletes participating in rugby union, soccer and touch football at the World Masters Games. Journal of the World Academy of Science, Engineering and Technology, 7, 1119-1123.

Williamson, J., \& Pahor, M. (2010). Evidence regarding the benefits of physical exercise. Archives of Internal Medicine, 170, 124-125. 